\title{
Study on Fiscal Transfer Payment System Reform in China-Based on the Perspective of a New Road to Urbanization
}

\author{
Shiqin Guo, Jie Zou \\ School of Economics and Management, Southwest Jiaotong University, Chengdu, China \\ Email: shiqinguo88@126.com, zoujie765@outlook.com
}

Received 20 July 2015; accepted 3 August 2015; published 6 August 2015

Copyright (C) 2015 by authors and Scientific Research Publishing Inc.

This work is licensed under the Creative Commons Attribution International License (CC BY). http://creativecommons.org/licenses/by/4.0/

c) (i) Open Access

\begin{abstract}
With rapid development of urbanization after China's reform and opening up, the transfer payment system has been reformed and improved constantly since it was implemented in 1995. But through empirical analysis on the implementation effect in this article, we find that the objective of China's transfer payment system is not effective realized. After further discussion on the current transfer payment system and problem analysis, we find there still are defects in the structure setting, measuring system, capital allocation method and other aspects. As a result, the article takes factor method as the breakthrough point to further reform and optimizes the current transfer payment system, and gives the corresponding countermeasures and suggestions to promote the healthy development of China's urbanization.
\end{abstract}

\section{Keywords}

Transfer Payment, System Reform, New Road to Urbanization

\section{Introduction}

With the speed development of urbanization since 1980s, China's economy, science, technology, education, culture and other industries have developed rapidly, and have made remarkable achievements. But at the same time of industrial upgrading and economic prosperity, the quality of urbanization is not high. The gap among cities and towns has widened, the regional development is imbalance and the basic public service supply is inequality due to the excessive emphasis on traditional urbanization speed, quantity and scale [1]. Therefore, for the transformation of the development mode and improvement of the quality of urbanization, the central government has greatly increased its support to local finance and the transfer payments. But there are still many defects in financial transfer payment system at present stage. Its effect in balance development gap between re- 
gions is little [2]. Therefore, in the strategy transition period of new urbanization, this article takes factor method as a breakthrough point, deep explored the reform direction of China's transfer payment system to improve its nature of scientific, normative, transparency and fairness, and to really play the function of balancing regional development difference. Deep research on transfer payment system can not only enrich the theories of transfer payment system and provide essential references and guidance, but a more scientific, fair, efficient transfer payment system can also provide reliable financial indemnity for the new pattern urbanization of China, and has an important practical significance to promote the sustained and healthy development of China's new pattern urbanization. The potential innovation of this article is to analyze the implementation effect and existing defect of China's transfer payment system after establishment from the unique point of view of new urbanization, and on this basis propose the breakthrough point of factor method to reform the transfer payment system. The deficient aspect of this article is that it just provides corresponding countermeasures and suggestions for the system reform from the macroscopic view, but not designs out specific factor method reform plan, which is the author's subsequent research content.

\section{The Evolution of Transfer Payment Scale in the Progress of Urbanization in China}

Since the late 1970s, with the pushing of the reform and opening-up policy, China's urbanization began accelerated development; especially since the mid-1990s, the urbanization speeded up obviously, a huge social and economic development presented. Fiscal policy is an important lever of national macroeconomic regulation and control, as an important product of the fiscal decentralization, scientific and reasonable transfer payment system can effectively make up the local financial gap, and narrow the gap between regional financial resources. China's transfer payment system was established in 1994, together with the "revenue-sharing-scheme" reform. With the elevation of urbanization level and rapid increase of social economy, the revenue of central government increases heavily, the "two proportions" are improved greatly. From 1993 to 2013, the proportion of revenue in GDP was improved from $12.6 \%$ to $22.7 \%$, the proportion of central government revenue in national revenue was improved from $22 \%$ to $46.6 \%$; China has sufficient fiscal resources to carry out transfer payment. After 1995 , the transfer payment scale from central government to local government increased year by year, as showed in Figure 1.

\section{The Effect of China's Financial Transfer Payment System in Background of Urbanization}

Through fiscal and taxation reform over the years, China's financial system has been changed from constructive finance to public finance. In recent years, with continuous increasing support from central government to local

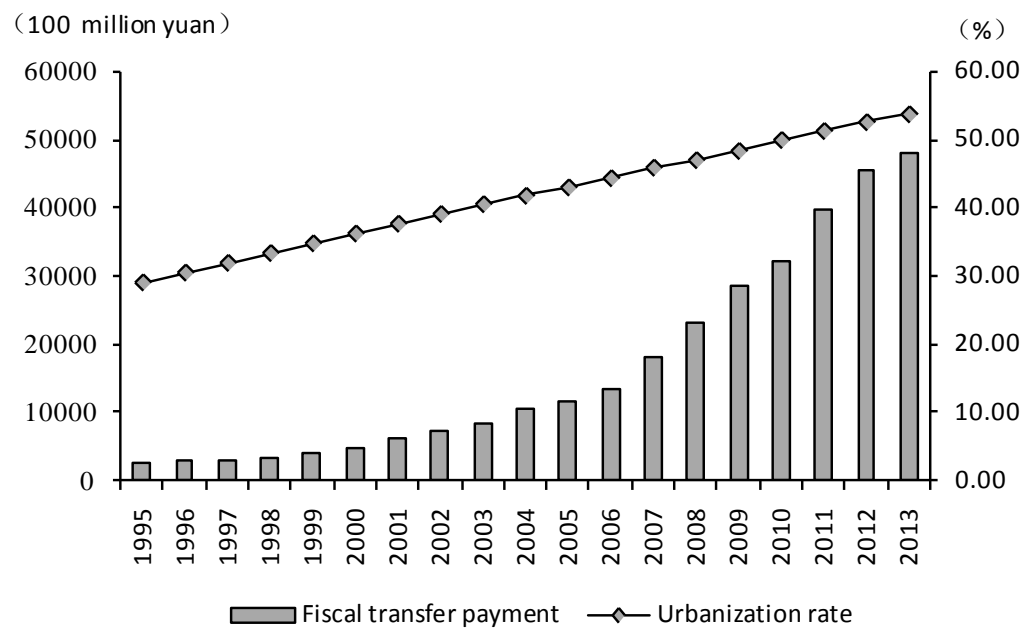

Figure 1. The urbanization level and transfer payment scale from cectral to local government from 1995-2013. a. Data source: “Finance Yearbook of China” (2014) and "China Statistical Yearbook" (2014). 
fiscal, some effects have been achieved in fetching up the gap of local financial resources and promoting regional economic development [3]. But after reality investigation, we found that the equalization function of transfer payment didn't reach the desired effect.

\subsection{The Regional Gap between Rich and Poor Was Not Reduced Significantly}

The GDP per capita is a best indicator to reflect economic development level and affluence level of one area; it can true reflect the status of the region's economic development. Data in Table 1 shows that although the ratio gap of GDP per capita of the middle, west, northeast and east was narrowing, the absolute difference was increasing. Generally, the gap between rich and poor between eastern area and the central and western area is expanding. The ratio of GDP per capita of the east, middle, west and northeast area was 1:0.37:0.37:0.56 in 2004, and 1:0.52:0.53:0.73 in 2013. At the same time, the absolute difference of GDP per capita between the east area and the middle, west and northeast area was changed from 15,446 Yuan, 16,325 Yuan and 10,769 Yuan in year 2004 to 31,970 Yuan, 31,647 Yuan and 18,478 Yuan respectively in year 2013. The richness degree of east area is the highest; the gap between rich and poor between regions didn't show obvious reducing, even increased from the perspective of absolute value.

\subsection{The Financial Resources Gap among Local Governments Is Comparatively Large}

China began to implement transfer payment of transition period in 1995, since 1998, the subsidy obtained from central government by each province has been increasing substantially. With the implementation of strategies of development of western region, rejuvenating old northeastern industrial bases and rising of central China since 2000, the transfer payments quantity to western region, central China, and northwest from the central government increased greatly, compared to the eastern region. At the same time, the general transfer payments to eastern region were reduced accordingly, ${ }^{1}$ in order to promote financial resources balance among the provinces [4]. Through observing the revenue per capita, we can find that its gap was narrowing gradually among the four regions. For example, the ratio of revenue per capita of the eastern region to northeast region, central region and western region was 1:0.40:0.24:0.25 in 2004, increased to 1:0.45:0.29:0.32 in 2009, and further increased to 1:0.56:0.39:0.46 in 2013. But from the point of regional horizontal level, financial resources per capita of the central and western region is still less than half of the eastern region. It can be seen in Figure 2 that the national financial revenue per capita is 5664 Yuan in 2013, the provincial revenues per capita have a sharp growth, compared to 2009. But in the top 5, only Liaoning province is located in the northeast, due to its earlier industrial development, the other four provinces (municipalities directly under the central government) like Beijing, Shanghai, Tianjin and Jiangsu are all belong to the eastern developed region. The last 5 provinces are all located in Midwest, the revenue per capita is 3067 Yuan in Tibet, 3047 Yuan in Hunan, 2803 Yuan in Guangxi, 2567 Yuan in Henan and 2354 Yuan in Gansu, far below the national average level. The revenue per capita of Beijing,

\begin{tabular}{ccccccc}
\multicolumn{6}{c}{ Table 1. The difference of GDP per capita over the country from year 2004-2013 (Yuan). } \\
\hline Year & Country & East & Middle & West & Northeast & Ratio of GDP per capita \\
\hline 2004 & 12336 & 24478 & 9032 & 8153 & 13709 & $1: 0.37: 0.33: 0.56$ \\
2005 & 14185 & 27379 & 10636 & 9827 & 15588 & $1: 0.39: 0.36: 0.57$ \\
2006 & 16500 & 31323 & 12256 & 11492 & 17901 & $1: 0.39: 0.37: 0.57$ \\
2007 & 20169 & 36333 & 14722 & 13827 & 21197 & $1: 0.41: 0.38: 0.58$ \\
2008 & 23708 & 41467 & 17773 & 16782 & 25500 & $1: 0.43: 0.40: 0.61$ \\
2009 & 25608 & 45614 & 19828 & 19289 & 28094 & $1: 0.43: 0.42: 0.62$ \\
2010 & 30015 & 50793 & 24249 & 23482 & 33677 & $1: 0.48: 0.46: 0.66$ \\
2011 & 35198 & 57936 & 29317 & 28783 & 40680 & $1: 0.51: 0.50: 0.70$ \\
2012 & 38420 & 62533 & 32462 & 32426 & 45258 & $1: 0.52: 0.52: 0.72$ \\
2013 & 47047 & 67273 & 35303 & 35626 & 48795 & $1: 0.52: 0.53: 0.73$ \\
\hline
\end{tabular}

b. Data source: “China Statistical Yearbook” (2005-2014).

${ }^{1}$ The appellation “financial resources transfer payment” has been changed to "general transfer payments” in 2009. 


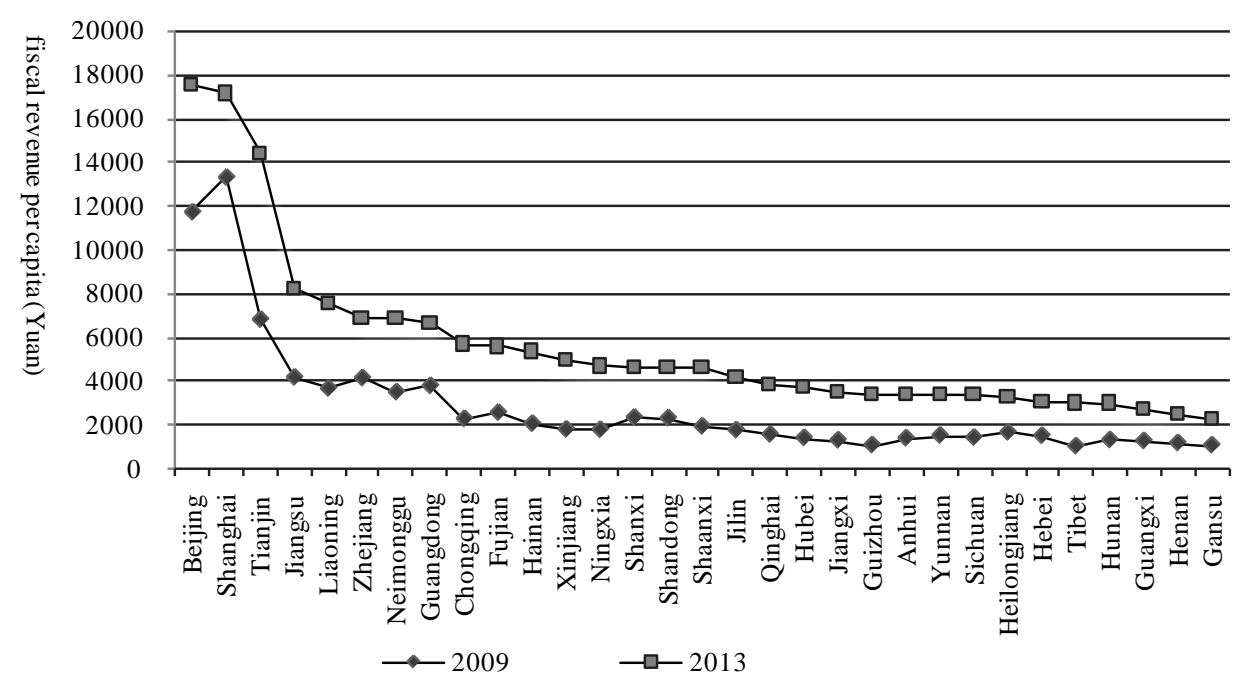

Figure 2. Provincial fiscal revenue per capita in 2009 and 2013. c. Data source: calculated from “Finance Yearbook of China” (2010, 2014) and “China Statistical Yearbook” (2010, 2014).

having the highest revenue per capita, is 7.4 times of the lowest level province, Gansu. Thus, the financial gap between regions is still very large in China, under the background of new urbanization, the Midwest region still need strong national fiscal policy support as its large population, lower starting point, and big demand on public service.

\subsection{Lower Overall Level of Public Service}

In general, with the enhancement of China's economic power after the reform and opening up, national fiscal expenditure has been increasing constantly. The expenditure of 1994 is 579.262 billion Yuan, and has risen to 14.02121 trillion Yuan in 2013, which is 24.2 times of 1994, with an average annual growth rate of $18.26 \%$. At the same time, the basic public service expenditure increased year by year; Table 2 shows that the growth rate is more than $10 \%$ in recent years, even up to $19.29 \%$ from 2007 to 2013, providing an effective guarantee to the financial supply of public services. Although the government paid increasing attention to the development of public services in recent years, the proportion of expenditure for basic public services in the fiscal expenditure did not increase obviously, hovering in the level of $57 \%$, which still has some distance compared with the developed countries. In some developed countries even some developing countries, the lowest level of the proportion is above $60 \%$ in 2005 [5]. It could be concluded that the public service level is not high in China, the financial supply of which still need to increase.

\subsection{The Supply of Basic Public Service Is Imbalance between Regions}

The financial investment from local government is the main financial resources of basic public services. And it had significant influence on urbanization development [6]. Along with the advancement of urbanization and the development of export-oriented economy, differences appeared between the regional industrial structure, capital factor and labor accommodation. Different urbanization and economic level affects the balance of the basic public service supply [7]. Supposing the government departments are efficient in the public service activities, and financial resources supply is the main factor influencing the equality of basic public services, the variation coefficient of urbanization level, fiscal expenditure per capita, and basic public services expenditure per capita can reflect the regional differences in the levels of urbanization and basic public services.

Figure 3 shows that the provincial gap of variation coefficient of urbanization rate is not obvious during 2004 and 2013, retaining between from 0.26 to 0.35 . The variation coefficient presented decline trend since 2005, indicating the provincial gap of urbanization rate has been decreasing. The change trend of the variation coefficient of fiscal expenditure per capita is similar with the variation coefficient of urbanization rate, dropping year by year; the dropping trend is evident between 2005 and 2009, and is not obvious between 2010 and 2013. The provincial differences of basic public services per capita also presented a decline trend after 2007; the dropping 
Table 2. China’s fiscal expenditure and basic services expenditure. ${ }^{2}$

\begin{tabular}{ccccc}
\hline Year & $\begin{array}{c}\text { Total fiscal expenditure } \\
\text { (100 Million Yuan) }\end{array}$ & $\begin{array}{c}\text { Basic public service expenditure } \\
\text { (100 Million Yuan) }\end{array}$ & $\begin{array}{c}\text { Growth rate of basic } \\
\text { public service (\%) }\end{array}$ & Proportion (\%) \\
\hline 2007 & 49781.35 & 28522.70 & - & $57.30 \%$ \\
2008 & 62592.66 & 35692.51 & $25.14 \%$ & $57.02 \%$ \\
2009 & 76299.93 & 42912.89 & $20.23 \%$ & $56.24 \%$ \\
2010 & 89874.16 & 50558.13 & $17.82 \%$ & $56.25 \%$ \\
2011 & 109247.79 & 62351.33 & $23.33 \%$ & $57.07 \%$ \\
2012 & 125952.97 & 73639.81 & $18.10 \%$ & $58.47 \%$ \\
2013 & 140212.10 & 82199.01 & $11.62 \%$ & $58.62 \%$ \\
\hline
\end{tabular}

d. Data source: “Finance Yearbook of China” (2008-2014).

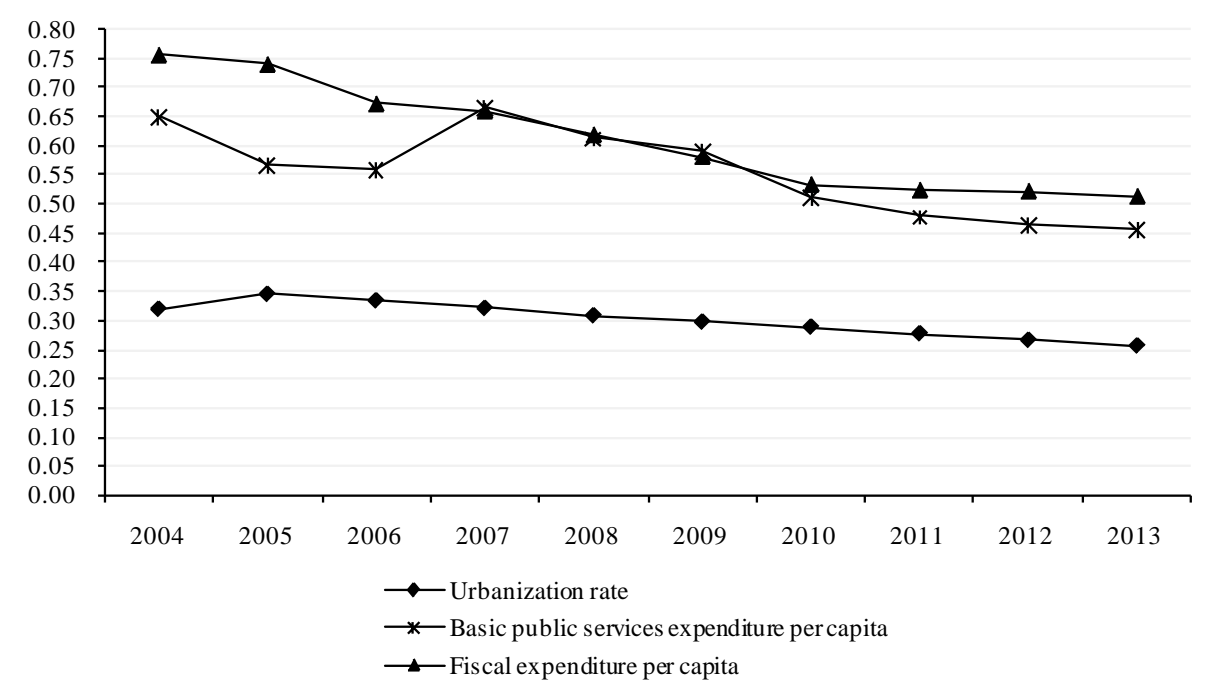

Figure 3. The provincial variation coefficient of urbanization level, fiscal expenditure per capita, and basic public services expenditure per capita from 2004 to 2013. ${ }^{3}$ e. Data source: calculated from the "Finance Yearbook China” and the “China Statistical Yearbook” (2005-2014).

trend is evident between 2007 and 2010, and is not obvious between 2011 and 2013. It suggested that, in recent 10 years, with the rapid development of urbanization in China, the development gap between regions is gradually narrowing in overall, the gap of fiscal expenditure per capita and basic public service expenditure per capita has narrowed, but other region differences are still large. The financial support of basic public service to the underdeveloped regions should increase, or there will be certain amount of conditionality to the advancement of new urbanization.

\section{Problem Analysis of the Current Financial Transfer Payment System of China}

\subsection{The Financial Transfer Payment Structure Existing Defects}

The existing transfer payment forms from central government to local government are tax rebates, general

${ }^{2}$ Note: The spending projects of basic public services mainly include national defense, public security, education, science and technology, culture, sports and media, social security and employment, health, energy conservation, environmental protection, urban and rural community affairs, etc. Due to financial statistics caliber changing in 2007, this article only selects the data after 2007, in order to facilitate comparative analysis.

${ }^{3}$ Note: In 2007, China implemented reform of classification project setting of government revenue and expenditure, financial statistics caliber changed, the data project of the basic public services expenditure included stylistic broadcasting, education, science, health care, pension and social welfare, retired administrative institution, social security, national defense, administrative management, armed police, courts and city maintenance in 2006 and before, while the data project contained defense, public security, education, science and technology, culture and sports and media, social security and employment, medical and health, environmental protection, urban and rural community affairs between 2007 and 2013. Although some differences existed between the statistical calibers, the main content remained the same. 
transfer payments, and special transfer payments. Through constant reform and perfecting, the proportion of each payment in the total transfer payments changed a lot, but its unreasonable structure has not changed fundamentally, as demonstrated in Table 3.

The tax rebates quota is calculated on the basis of tax source with "radix method", which conflicted with the ultimate goal of public finance and exacerbated financial inequality between regions [8]. It could be seen from Table 3 that the rebate proportion was up to $46.2 \%$ in 2001, and declined to $10.4 \%$ in 2013 . Although the proportion dropping year by year, the value was still high, influencing the strength of balancing transfer payment. The projects of special transfer payment involve the vast majority of public service; its range is too wide. In the process of capital allocation, administrative examination and approval exists, together with the situation that the economic backward area has a bigger pressure on capital supporting will lead to a large number of special transfer payment funds flowing to the developed areas, intensifying regional financial disparity. After the implementation of active fiscal policy in China in 1998, the proportion of special transfer payment increased sharply, from $18 \%$ in 1996 to $50.6 \%$ in 2001 , and to $56.1 \%$ in 2008 . The central government adjusted the transfer payment structure in 2009, after when the proportion of special transfer payment began to decrease year by year, but still reach 39.4\% in 2013, still occupied an important position in the transfer payments structure. In the transfer payment structure of China, only the general transfer payment adopts a more objective, scientific and standardized method to measure and allocate; it plays a positive role on balancing region financial gap and promoting public service equalization; its position needs to be strengthened. Data in above table shows that, although the proportion of general transfer payment increased during 2001 and 2008, the increasing speed is not obvious; the proportion is less than $20 \%$ of the total payments, while the proportion of tax rebates and special transfer payment is more than $80 \%$, making the scale of general transfer payments severely restricted and the strength small. Although the proportion of general transfer payments has increased dramatically since 2009, the tax rebates and special transfer payments still share larger proportion, so its equalization function cannot play effectively.

\subsection{The Scientific Degree of the Measurement Method of Transfer Payment Needs to Be Strengthened}

The allocation basis and measuring system are the core contents of financial transfer payment system; it is the guarantee of achieving the goal of fiscal transfer payment [9]. Scientific and complete allocation basis and measuring system is directly related to the rationality and scientific nature of a nation's redistribution, and the efficiency of capital allocation. At present, China's funds allocation method of transfer payment basically has two kinds, namely base method and factor method. The base method is based on the previous year, determining the transfer payment quota according to financial affordability and social economic development situation. The factor method is based on the goal of fiscal transfer payment, determining the transfer payment quota according to all the factors affecting region financial revenue ability and expenditure demand. After tax reform in 1994, base

Table 3. The financial transfer payment structure from central to local government and its proportion from 2001-2013 (billion Yuan).

\begin{tabular}{|c|c|c|c|c|c|c|c|c|}
\hline \multirow{2}{*}{ Year } & \multicolumn{2}{|c|}{ Tax rebates } & \multicolumn{2}{|c|}{ General transfer payment } & \multicolumn{2}{|c|}{ Special transfer payment } & \multicolumn{2}{|r|}{ Total } \\
\hline & quota & proportion (\%) & quota & proportion (\%) & quota & proportion (\%) & quota & proportion (\%) \\
\hline 2001 & 233.5 & 46.2 & 16.1 & 3.2 & 256.0 & 50.6 & 505.6 & 100 \\
\hline 2006 & 393.0 & 39.8 & 153.0 & 15.5 & 441.2 & 44.7 & 987.2 & 100 \\
\hline 2008 & 428.2 & 24.1 & 351.1 & 19.8 & 996.2 & 56.1 & 1775.5 & 100 \\
\hline 2009 & 488.7 & 17.1 & 1131.7 & 39.6 & 1236.0 & 43.3 & 2856.4 & 100 \\
\hline 2010 & 499.3 & 15.4 & 1323.6 & 41 & 1411.2 & 43.6 & 3234.1 & 100 \\
\hline 2011 & 504 & 12.6 & 1831.1 & 45.9 & 1657 & 41.5 & 3992.1 & 100 \\
\hline 2012 & 510 & 11.2 & 2148 & 47.3 & 1882 & 41.5 & 4540 & 100 \\
\hline 2013 & 510 & 10.4 & 2452.8 & 50.2 & 1927.2 & 39.4 & 4890 & 100 \\
\hline
\end{tabular}

f. Data source: calculated based on “China Statistical Yearbook” 2002, 2007, and “Zhongguo Caizheng Jiben Qingkuang” (2008-2013). 
method was used for transfer payment in the transition period in China. Taking local real income in 1993 as base, turning certain proportion of the value-added tax and consumption tax to central government, and returning most of them back to local place in the form of tax rebates. On base of 1993, the tax rebates quota increased with a coefficient of 1:0.3 to the growth rate of national value-added tax and consumption tax, the coefficient increasing year by year. This method ignored the objective difference between region fiscal revenue ability and expenditure demand, and has no objective and scientific standard, leading to the lacking of normative and scientific fiscal transfer payment system; a large number of financial resources of central government were diverted, financial resource used to balance region difference was deficient; the equalization function of financial transfer payment was difficult to achieve. After years of reform, tax rebates quota has fallen sharply, but it still occupy a certain proportion in the transfer payments, which is harmful to narrow the gap between regional economic and social development and realize the regional harmonious development.

\subsection{The Application Scope of "Factor Method" in Current Fiscal Transfer Payment System Is Narrow, and Defects Exist in Application Process}

Factor method has been used for fiscal transfer payment in China after the implementation of "transfer payment policy in transition period" in 1995, but the funds allocated by this method is limited, only takes $0.5 \%$ of the financial revenue of central government. Only the general transfer payment takes this method to measure payment quota until now, the payment amount and scale of which is very small. Although the proportion has increased in recent years, the tax rebates and special transfer payments still accounts for an absolute majority, closing to 50\% in 2013. The application of factor method in transfer payment system is still not mature; the unbalanced fiscal transfer payment system has not been fundamentally touched.

The key of factor method using is factor selection and weight determination, there are three main methods to select and measure the factors: factor scoring method, regression method and coefficient adjustment method. The principle of factor scoring method is to determine factors that influence local fiscal expenditure level and their weights, then score the local place by scientific scoring standards, and then calculate the nation's total score by summing up the score of each place, then calculate the financial expenditure value of each score by dividing the national financial expenditure by nation's total score, and multiply the financial expenditure demand score of each region by the financial expenditure value of each score at last and get the standard quota of each region's financial expenditure. The factor scoring method is intuitive and understandable, but it's too simple, only considering the financial expenditure demand of each region, without taking the fiscal revenue ability and fiscal effort into consideration. The regression method utilize quantitative analysis, to find out factors influencing academic financial expenditure and revenue and calculate their effect by regression analysis; and then use existing data to establish a multiple regression model of standard fiscal expenditure and fiscal revenue, and establish a standard fiscal balance coefficient model on this basis. Finally, making appropriate adjustment on fiscal transfer payment, according to the region balance coefficient. The factor regression method is complex, because the data adopted must be accurate, complete and comprehensive. Measurement accuracy of this method is easy to be affected, which could lead to big error. At the same time, this method only focus on the transverse fiscal imbalance between regional governments, but ignore the longitudinal fiscal imbalance between different levels government. The principle of coefficient adjustment method is to evaluate regional fiscal supporting population and fiscal expenditure standard, and calculate its standard financial expenditure, at the same time of calculating regional financial revenue according to each tax base and the statutory tax rate; and then make necessary coefficient adjustment according to regional economical development level, population density, natural endowment, ethnic areas and other factors. The coefficient adjustment method conforms to China's reality relatively and has certain accuracy, but as the current statistical system in China is underdeveloped, the collection and statistical process of financial data is imperfect, and the database is not sound enough, this method is vulnerable to artificial factors, and has big difficulty in actual application.

\section{Reform Deepening Strategy of Transfer Payment System in the Background of New Urbanization}

Through above analysis, we can see that the rigid demand for public finance of each region was increasing gradually. In order to solve the defects existing in the current transfer payment system in China, some scholars put forward the opinion that reforming the fiscal transfer payment system by replacing the "base method" by 
"factor method", which was agreed in theoretical and practical level in our country. This paper suggested deepening the reform from the following aspects, to promote the optimization of the transfer payment system in China.

\subsection{Further Deepening the Reform of Fiscal Decentralization and "Revenue-Sharing-Scheme", Insisting on Advancement of the "County Directly Administrated by Province" Administration System, Making Well Conditions for the Implementation of "Factor Method" Payment System}

The biggest problem remaining in the reform of "revenue-sharing-scheme" in 1994 was the incompleteness of fiscal decentralization, which only stipulated the limits of authority in finance and work between the central government and provincial government, but did not clear the limits of authority in finance and work of local government below province. This lead to moving up of property rights, and devolving of governance, especially for the governments in basic level, they shoulder many expenditure responsibilities in public affairs, but are short of necessary financial security due to the moving up of property rights. This situation can hardly meet the demand for public service in basic level in the rapid process of urbanization, and further restrict the advancement of new urbanization. Therefore, China must strengthen the fiscal decentralization reform, reduce the administrative level, insist on advancement of the "county directly administrated by province" administration system, to make well system conditions for the implementation of scientific and standard "factor method" transfer payment system.

\subsection{Clearing the Target of Transfer Payment, Extending the Application Range of Factor Method, and Optimizing the Structure of Transfer Payment}

At present, the primary goal of transfer payment in China is to balance the financial resources gap between regions, and realize equalization of basic public service. Against the irrationality existed in current transfer payment structure, this article provided three suggestions. Firstly, considering reducing and finally canceling tax rebates year by year, gradually abolishing the unreasonable factors remaining from the old system, and clearing obstacles to achieve equal transfer payments. Secondly, setting and adjusting projects of the general transfer payments reasonably, according to the target and function of transfer payment. The payment targets and subjects of the current general transfer payment is too excessive, some subjects stipulate direction and purpose of payment, possessing the nature of special transfer payment. Among all the subjects of general transfer payment, only the equalization transfer payment utilized factor method. Therefore, the government should constrict the subjects of general transfer payment, extend the application range of factor method, increase expenditure scale, especially for the shortage area of financial resources, and truly endow rights to local government in reasonable use and arrangement of funds, in order to realize regional equalization of basic public service. Thirdly, reducing the projects and scale of special transfer payments, implementing strict examination and approval and supervision. The special transfer payments cause too large supporting pressure to local governments. It is easy to weaken its financial ability as a whole. The project examination and approval are greatly influenced by artificial factors, and the expenditure area is too wide, which lead to problems such as scattered distribution, overlapping functions and confused management, reducing the use efficiency of special funds; it is difficult to realize specific target. Therefore, subject setting of the special transfer payments should concentrate on the local public services having strong revenue surplus, clear the payment targets, functions, and conditions, distribute in accordance with the standard, determine the payment scale and proportion reasonably, and supervise the utilization of funds.

\subsection{Reforming the Measurement System of General Transfer Payment by Factor Method, Establishing a Objective, Scientific, Standard and Unified General Transfer Payment System with a Main Body of Factor Method from the Central Government to Province, and from Province to City and County}

At present, it has been utilized maturely in the world to measure and calculate standard fiscal revenue and expenditure, and its parameters by factor method, the typical countries are Australia, Germany, Japan, Canada etc. This method reduces the interference of man-made factors, has high transparency, and can effectively balance the financial gap between regions. The core of implementation of factor method is how to select the factors and 
determine their weights. The following three aspects should be considered in factor selection: financial ability factor, expenditure demand factor and cost variance factor. In China, the ethnic factor should also be concluded [10]. The key for the determination of factor rights is to calculate out the weight of each factor in determining revenue ability and expenditure demand, from the perspective of quantitative analysis [11]. Based on the reality of China and the advantages and disadvantages of all kinds of factor selection methods, it is worth considering to combine the regression analysis method and coefficient adjustment method. On the basis of regression analysis, selecting the factors that can objectively reflect regional revenue ability and expenditure demand, such as population, GDP per capita, population density, age structure, degree of fiscal effort, urbanization degree, economic development level, natural conditions, the proportion of ethnic minority population and other factors. In addition, with the advancement of urbanization, a large number of rural surplus labors transfer to towns, where the demand for public service expenditure increases. Therefore, the floating population factor should be brought into the equalization category of basic public service, implementing the policy of "payment goes along with people". At last, calculating the financial self-sufficiency according to regional financial revenue ability and expenditure demand, and measuring the transfer payment quota combining this basis and the regional cost difference and fiscal effort degree.

\subsection{Improving the National Statistical System, Making Sure the Data is Scientific, Comprehensive, and Complete, Providing Reliable and Precise Data Basis for the Funds Measurement and Allocation of Fiscal Transfer Payment in Accordance with the Factor Method}

Carrying out "factor method" measurement for transfer payments by econometric regression analysis method needs to collect a large amount of data. Whether the measurement formulas and systems designed are scientific, objective, just and strict or not are decided by the truth and comprehensiveness of data adopted. At present, China's statistical system is not perfect, situation like artificial modification and data falsification exist abundantly. Therefore, it's necessary to strengthen the construction of statistical system of each industry, improve the professional quality of statistical staff, and ensure the truth of statistical data, in order to make sure the statistical data acquisition is more convenient, efficient, real and comprehensive.

\section{Conclusion}

Through above analysis we can see that, in the present background of new urbanization emphasizing quality promotion, regional coordination, and integration development of city and country, the inherent defects in the current fiscal transfer payment system make it unable to effectively change the status of regional financial disparity, and are not conducive to realize equal basic public services between regions, and hinder the smooth establishment of new urbanization in China. Only through further strengthening reform, abolishing the unfavorable factors in old system, promoting fiscal transfer payment system reformation with factor method, improving its objectivity, transparency, standardization, scientific, and the efficiency of funds usage, and strengthening the function of the financial balance, it could balance the gap of regional financial resource, provide powerful financial support and protection for construction of new urbanization in China, and promote regional coordination, social stability and economic growth.

\section{References}

[1] Wei, H.-K. (2014) A New Road to Urbanization with Chinese Characteristics. Social Sciences Academic Press, Beijing, 13-25.

[2] Zeng, H.-Y. (2012) Study on Standardization Systems for Equalization of Basic Public Services and Assessment Method of Fiscal Transfer Payment in China. Economic Research Journal, 6, 20-32.

[3] Fu, W.-L. and Shen, K.-R. (2012) Equalizing Transfer Payment and the Structure of Local Government’s Expenditure. Economic Research Journal, 5, 45-57.

[4] Song, X.-N., Chen, B. and Liang, R.-B. (2012) Can General Purpose Transfers Promote Basic Public Services? The Journal of Quantitative \& Technical Economics, 7, 33-43.

[5] Ju, H. (2006) Market Mechanism in Public Services: Theory, Methods and Techniques. Peking University Press, Beijing, 267-342.

[6] Zhou, Z.-Q. and Qiao, Z.-M. (2011) Financial Development, Input of Public Finance and Urbanization. Urban Studies, 
18, $17-20$.

[7] Zhang, X.-J. (2013) Research on the Synergy Effects of Policies between New Urbanization and the Equalization of Basic Public Services. Economy and Management, 27, 5-12.

[8] Tsui, K. (2005) Local Tax System, Intergovernmental Transfers and China's Local Fiscal Disparities. Journal of Comparative Economics, 33, 173-196. http://dx.doi.org/10.1016/j.jce.2004.11.003

[9] Ma, H.-T. and Jiang, A.-H. (2010) Financial Transfer Payment System between Governments. Economic Science Press, Beijing, 111-134.

[10] Zhong, X.-M. (1997) Discussion of Financial Transfer Payment System between Governments. Economic Research Journal, 9, 44-49.

[11] Shah, A. (1994) The Reform of Intergovernmental Fiscal Relations in Developing and Emerging Market Economics. Policy and Research Series 23, The World Bank, Washington DC. http://dx.doi.org/10.1596/0-8213-2836-0 